\title{
Discussion on the Mode of Ideological and Political Education in Engineering Major Based on the Motivation Attribution Theory
}

\author{
Lingfeng Tang ${ }^{1}$, Yaoyao Zhang ${ }^{1}$, Youmin Wang ${ }^{1}$ \\ ${ }^{1}$ School of Mechanical and Automotive Engineering, Anhui Polytechnic University \\ Anhui Polytechnic University \\ Wuhu, China \\ 1073045704@qq.com
}

\begin{abstract}
The ideological political education is in full swing in the universities. In view of the current mode and method of curriculum ideology activities carried out by various universities, it has been questioned that the effect of deliberately adding ideological and political elements to the teaching of professional courses. On the bas is of the theory of motivation attribution, it is suggested to start from the professional quality, the ideological and political accomplishment and the student's learning situation to correctly analyze the behavior attribution and carry out the necessary post-effect enhancement and proposed that education should be based on the classroom and not limited to the classroom, the space should be extended outside the classroom, the time should be extended before and after class, in addition, education should be personalized and guided by people, taught by things. Only by thinking about politics whenever and wherever people want can we achieve the goal of cultivating college students' morality.
\end{abstract}

Keywords-ideological and political education; motivation attribution; personalized education; teaching by thing; morality education

\section{INTRODUCTION}

At the Conference of Ideological and Political Work of National Higher Education, general secretary Xi Jinping stressed that classroom teaching should be utilized as the main channel, and all kinds of courses should go with the course of ideological and political theory to form a synergistic effect, so as to construct the pattern of educating the whole staff, whole course and curriculum[1]. Furthermore, regarding "morality education" as the fundamental task of education is a comprehensive educational idea. In recent years, in order to promote the development of ideological and political work of curriculum, many schools have organized " Ideological and political education " class competitions and required the participants to deeply explore the professional curriculum of ideological education resources; refine social responsibility, legal thinking, innovative spirit, practical ability, humanistic feelings and other elements; comb the elements of ideological and political education and the functions of ideological and political education in the course of professional curriculum; and integrate into each link of classroom teaching to realize the organic unity of "knowledge imparting" and "value leading".

Similar competitions were also organized in our school. From the competitions it can be seen that many teachers are working hard in the direction of the curriculum and thinking, carefully preparing the courseware, and doing everything possible to intersperse the elements of thinking and politics in the course, some of them even have a more ideological and political design, and the content is natural and comfortable and is easy to accept. However, most of the designs are relatively blunt, with obvious traces, and are likely to be overdesigned, especially the engineering courses. In addition, no matter how the teaching content is designed, the teaching model is still not out of the curse of indoctrination education. Then can the deliberately designed curriculum thinking achieve the desired effect, is it possible for each section of a specialized course to be interspersed with ideological content, and will such a design lead to a professional classroom of no fish or fowl? The current college students are very sensitive and realistic, so any deliberate and empty political preaching will arouse aversion, and the overly high-level and broad ideological education can hardly achieve good results, therefore it is necessary and farreaching to explore the ideological and political education model of engineering courses.

\section{MOTIVATION ATTRIBUTION THEORY AND IDEOLOGICAL AND POLITICAL COURSE}

The modern psychology divides the interpretation of behavioral attribution into self-attribution and attribution of others[2]. If the curriculum ideological work is regarded as an act, then the motivation (purpose) of which is to cultivate high-quality talents, and the correct attribution analysis of whether the ideological course has received good results can be helpful for all parties to adhere to the correct behavior. The American psychologist B. Weiner (1974) argues in his selfattribution theory that whether a behavior would be success or failure can be summarized into six reasons:

1) Ability. Assess whether or not the perpetrator is competent to the job; 
2) Efforts. Whether the perpetrator tried his best in the course of his work;

3) Work difficulty. The perpetrator judges the difficulty of the work;

4) Luck. Whether the perpetrator is lucky when he is engaged in a certain job and whether it is smooth;

5) Physical and mental condition. The physical and condition of the perpetrator while engaged in a certain work;

6) The reaction of others. Whether the perpetrator is assisted by others during the course of a certain work and whether the other person gives an objective evaluation after completion.

Hyde, a social psychologist, believes that the attribution of other people's behavior is generally based on two principles: One is called situational attribution or outward attribution, which considers the behavior of others is caused by situational factors; the other is called personal or internal attribution, which attributes the occurrence of others' behavior to the character of the agent or its condition.

In general, when making self-attribution, people often emphasize the external factors, such as "difficulty of work", while ignoring the internal and controllable factors, such as "effort", nevertheless, when interpreting other people's behaviors, they tend to emphasize inward attribution such as personality or attitude, while ignoring the importance of their situation. Although sometimes we have sufficient evidence to support the evaluation of other people's behavior, we are likely to underestimate the influence of external factors, and overestimate the impact of internal or personal factors, and there is always a preference for "people" and ignore the "right" attribution mentality. These two tendencies are likely to cause attribution errors, and thus misinterpret the cause of oneself or other people's behavior. Psychologists call this phenomenon a fundamental attribution error. For example, when a course test is over, the average score is very low, and the failure rate is very high, the teachers would think that the students did not work hard, and this is the intrinsic reason of the students. On the other hand, the students would think that the papers are too difficult, or the teacher did not focus on external factors such as priorities. Both sides are reluctant to look at their own reasons, and they have pushed the problem out, then the students are not willing to learn and the teachers have no confidence to teach so that the vicious circle is repeated. Conversely, if they find reasons from themselves, the students attributed the failure to their lacking efforts, and the teachers attributed it to their insufficiently explanation of the knowledge then the teaching process would transform into a good direction.

For college students, correct attribution can help them establish correct goals and make a proper role positioning, so that they will not be affected by the short-term experience of success or failure. The cultivation of achievement motivation could motivate and promote the college students, which can not only improve their initiative and determination to overcome difficulties and bring them into the state as soon as possible, but also guide the direction of college students and regulate their behavior. Hence, it is necessary to make full use of "attribution theory" in the ideological and political thinking of college students to cultivate students to establish correct achievement motives and help them to correct some unreasonable cognition. It is also necessary for the cultivation of students' healthy personality.

To achieve good results, the principles of psychology should be respect. On the one hand, teachers should make correct attributions of others for students' learning motivation; on the other hand, students should make rational selfattributions to guide them. Only teachers and students correctly position their roles and give reasonable expectations to others, can education become focusing and the goal be achieved. Teachers in the teaching process should not only focus on imparting professional knowledge, but also pay close attention to students' learning process, build learning community between teachers and students[3], adopt an equal and interactive "dialogue" mode, find their own sense of achievement from the progress of students, and actively participate in the learning of students to constantly improve their own ability. Ideological and political thought education should not only be in the classroom, but should run through the students' entire learning process, and find problems, find causes and solve problems anytime and anywhere, only in this way can the ideological and political work be gradually formed.

\section{ANALYSIS OF COLLEGE CLASSROOM SITUATION}

As one of the school's teaching supervisor, I went to some random lectures and sent the students class quality evaluation form, especially focusing on the new teachers, the teacher with lower evaluation (ranked in the bottom 10\%) and the teachers who won the award for excellence in teaching. There are about 200 forms recovered, including courses of liberal arts and science and engineering. The forms of supervision and class quality evaluation used by students are shown in Table I and Table II.

According to the record of the lectures, the situation in the class is concentrated in the following aspects:

In terms of teachers: Most teachers go to the classroom about 10 minutes in advance to prepare for class; the lecture content is skillful, the focus is outstanding, the hierarchy is clear and the rationality is strong. The teaching methods are different, a small number of teachers interact in the classroom, and professional teaching methods are basically using multimedia, a small amount of basic courses such as mathematics and mechanics use a blackboard.

In terms of students: Lateness is so common that breakfast is brought into the classroom for the first two classes in the morning; In some classrooms, only the students who are sitting in the first few rows are listening to the lectures, and the rate of students' attendance in class is generally low; all of them were playing mobile phones before the class, some students still keep staring at the mobile phone during the class. Some teachers severely criticize this phenomenon and even confiscate the mobile phone, while others choose to ignore it and let students play mobile game with headphones and watch video with a contenting smile. In class, whether the teacher 
indulges or not, the student's learning state is not optimistic. Students' eagerness of acquiring knowledge have become less, and the lazy students not only lost their motivation to learn, but also lost their awe of the classroom. From above we can know that there was a deviation in teaching and learning. According to the feedback information in the evaluation form of classroom teaching quality, majority of students require the classroom interaction, the increasing of the interest of the course, expect the professional authorities to participate in the lecture, increase the opportunity of field visits by enterprises, require the innovation of teaching methods, and require the combination of theory and practice. However, not a single piece of suggestion on the discipline management of strong classroom has never received, so the performance of the students in the classroom is no longer a major teaching can solve, the introduction of ideological teaching is of great urgency and pay close attention to students' ideological situation is imminent.

TABLE I. CLASSROOM TEACHING QUALITY EVALUATION FORM (SUPERVISOR)

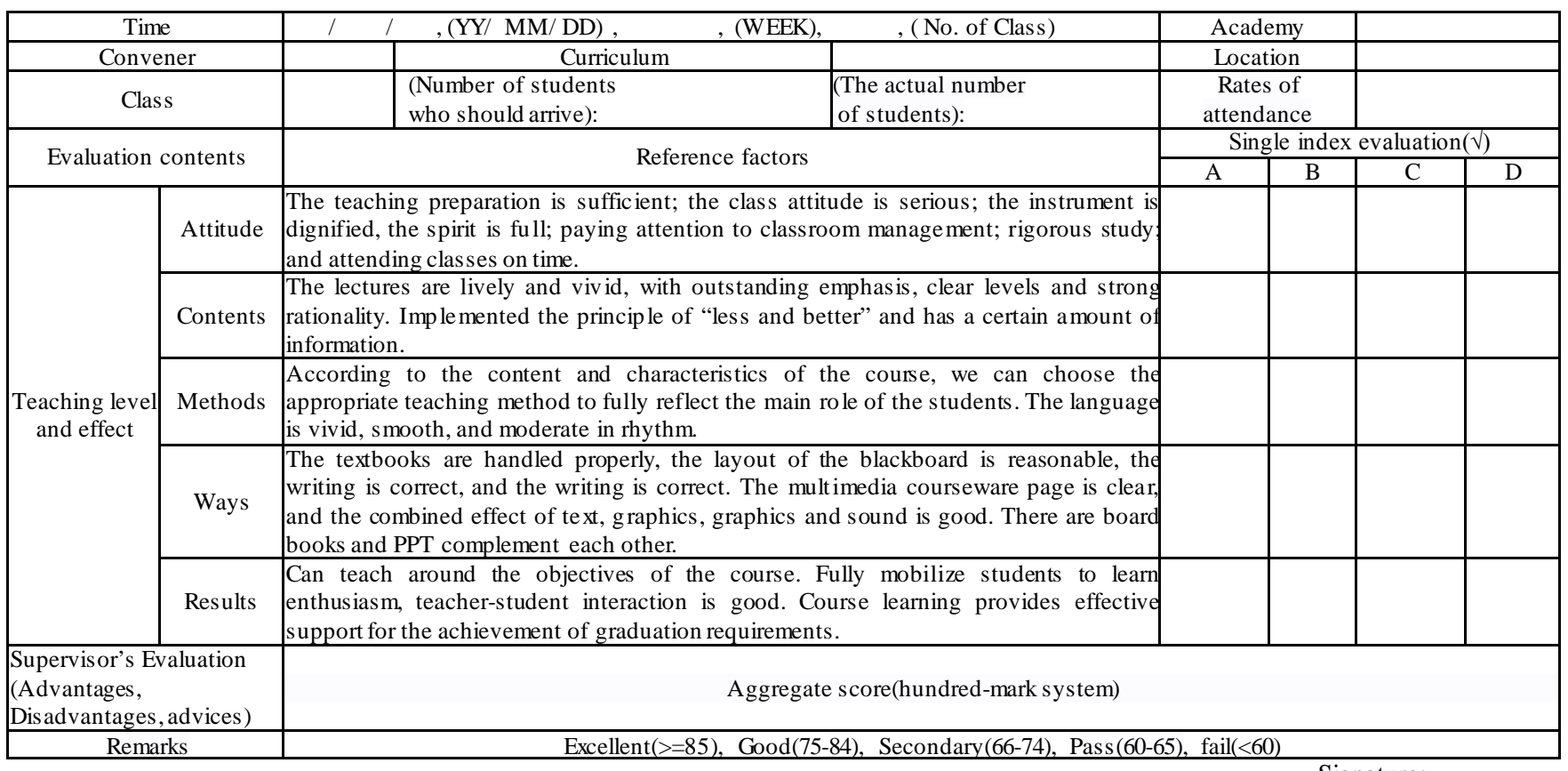

TABLE II. CLASSROOM TEACHING QUALITY EVALUATION FORM (STUDENT)

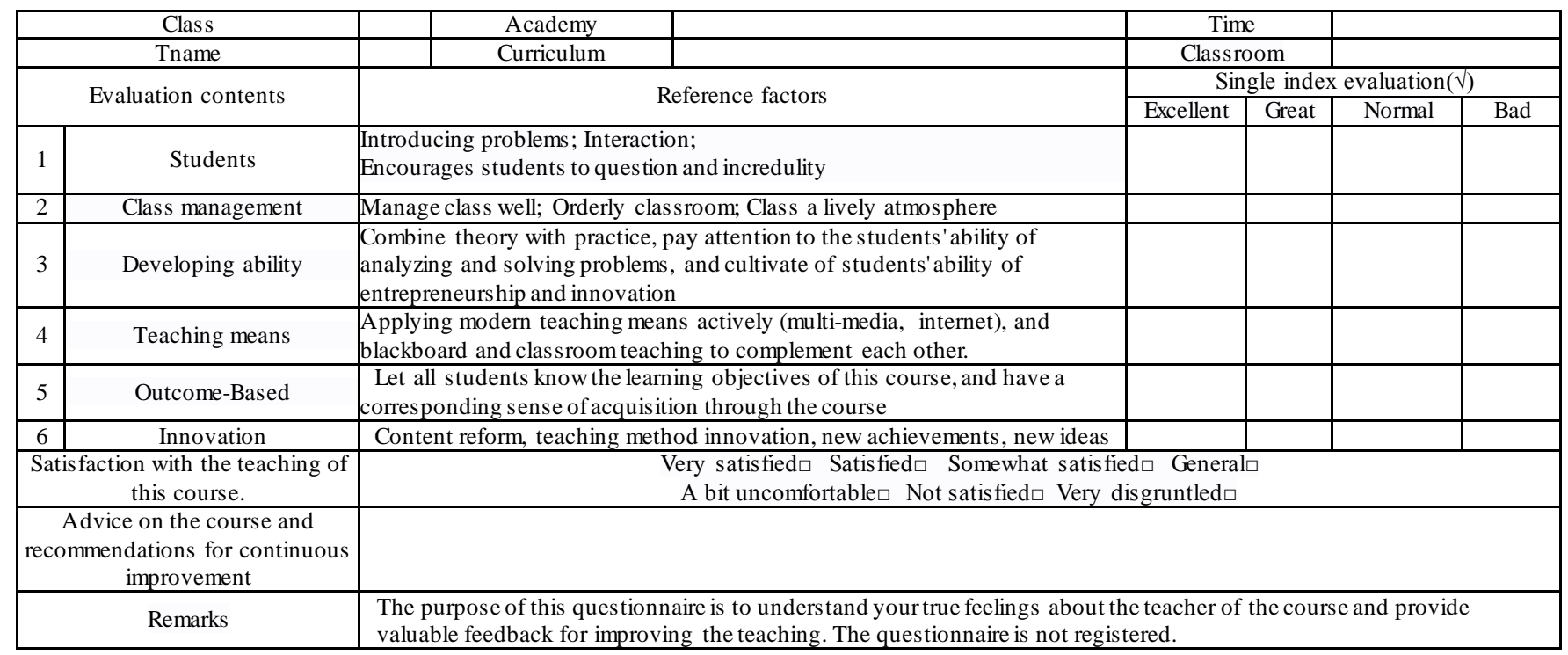




\section{DISCUSSION ON TEACHING MODE OF IDEOLOGICAL POLITICAL EDUCATION}

Einstein has meaningfully said: "Education with professional knowledge is not enough, through which he can become a useful machine, but cannot become a harmonious development of man." Suhomlinski has pointed out: "The process of cultivating a comprehensive and harmonious personality lies in that the educator who is caring about the perfection of every aspect of human characteristics, should never ignore this situation which the harmony of all aspects of human characteristics is determined by something dominant and primary. The dominant element that plays a decisive role in this harmony is morality[4]." Professional teachers should not only impart professional knowledge, but also pay attention to the cultivation of students' ideological and moral character and the teaching mode is no longer limited to 45 minutes in class, but education should be carried out anytime and anywhere.

1. Curriculum thinking should start from the classroom effect. It does not need to design deliberately, but must guide deliberately. The teacher should start with the details such as classroom record, students' instrumentation, lecture effect and students' sense of acquisition, carry out a reasonable attribution analysis for different situations, guide students with pertinence, and give correct psychological guidance and rational attribution to some students who are helpless[5]. Classroom discipline is a minor matter yet it is paramount; many little habits make a custom and many customs make a destiny.

Professional teachers should take professional development history and the future foreground as the keynote, and preach with their own growth experience, take the past excellent students as the model as well as taking inspirational stories around as the case, replace reproach with encouragement, communicate with students on an equal footing, establish a student-teacher learning community with students, and learn from each other. Facing the rapid development of information technology, there are many channels for students to acquire knowledge, apart from classroom, students can also use network resources to download video courses to learn more. Therefore, it is more important to stimulate students' learning motivation and create a good learning atmosphere in class, so that students will be full of expectations for the realization of course goals, and to cultivate students' interest in learning than simply imparting knowledge. At the same time the teachers also have to admit their own shortcomings in application of some modern technological means, so teachers must advance with the times, not only to learn the forefront of professional technology, but also to have a sense of time, to understand the development direction of the country, deeply study Xi jinxing's thought and theory system of socialism with Chinese characteristics for a new era, and have excellent political literacy, then we can grasp the pulse of the development of the times, maintain the communication and exchange of ideas of generation gap with students, and promote students' learning in an all-round way by demonstrating ourselves. Course ideology should avoid deliberate design and indoctrination. Education is not something to tell nor be told, but an active and constructive process. Only by establishing the 'teacher-student learning community", restoring the "learning ability", and changing the indoctrination education model into the active learning mode of activity, cooperation and reflection can the classroom efficiency be fully brought into play.

2. Morality education should be guided by people and taught at any time any place. The ultimate goal of ideological and political education is the morality education, while the classroom time is very limited, so that education should be based on the classroom but not limited in classroom, the space should be extended outside the classroom and the time should be extended before and after class and education should be personalized and guided by people, taught by things in no shape. Modern means of communication is abundant, so that the college teachers, no matter is working on ideological and political teaching or professional teaching, should take proper way to keep smooth communication with students, should trust the students and make them willing to speak out their suffering and confusion, give correct attribution analysis in time, guide them vary with each individual and teaches them vary with different situation, and makes ideological and political work individualize and permeate in every aspect of study and life. Of course, "teach people" must first have to" teach oneself", the essential requirement of " setting high moral values "is that college students have a clear cognition and practice on China's mainstream ideology and consciously practice it, for which, teachers must strengthen their political theory and have a firm communist belief. In Jul 1st speech, General Secretary Xi Jinping specifically stressed:" Theoretically not thorough, it is difficult to convince people "," Theoretically sober, then political can be determined. The firm ideal belief must be based on the profound understanding of Marxism, which is based on the deep grasp of the law of history[6]. "Establishing a community of teachers and students, learning and making teachers and students work together to make progress should be a beautiful human landscape in modern civilized universities.

\section{CONCLUSION}

1. The theory of self-attribution emphasizes that the achievement of achievement depends on different attributions of success or failure in past work. If success and failure are attributed to their own efforts, it will enhance the persistence of future efforts. Conversely, if success and failure are attributed to the fact that the ability is too low and the task is too heavy, it will reduce the persistence of their own efforts. Luck or opportunity is an unstable external factor, it will lead to the persistence of "waiting for the rabbit" if excessively attributed to this factor, and it is also disdainful for those with high achievement needs. In conclusion, only when the cause of failure is attributed to controllable destabilizing factors inside and outside, that is, the degree of effort is not enough, the perpetrator can further adhere to the original behavior. Therefore, students who are active in performance must be given enough praise and encouragement to persist in their positive state, and students with negative performance must be given enough patience to guide them to have a correct attribution for their own behavior as well as continue to persist 
in the effort behavior to achieve the purpose of education.

2. To view our teachers, we must consider the resistance and negative behavior of the students more from the external situational factors and strive to create a good learning atmosphere for the students in the course of education, so as to build up their confidence in correcting their own course, but not to attribute the mistakes to the students' intrinsic personality factors, which will make them lose their confidence and throw the handle after the blade. Education will make people in the achievement of incentive changes and promote the development of motivation, the focus of curriculum thinking is to teach students believe that efforts are not always the same and the goal is to take morality education, and to adapt to the development of the new era.

\section{ACKNOWLEDGMENT}

The work described in this paper was fully supported by the project of the "Quality Engineering Project of Anhui Education Department, Distinguished Teacher Workshop of Lingfeng Tang, and 2016msgzs009”.

\section{REFERENCES}

[1] Zhang Shuo. Ideological and political work throughout the whole education teaching process, create a new situation for the development of China's higher education business[N]. People's Daily,2016-1209(001).( In Chinese)

[2] Zhang Chunxing. Modern Psychology [M].Shanghai People's Publishing House, 1986.( In Chinese)

[3] WEN Xiang. The Application of the "Learning Community" Teaching Model in the Ideological and Political Course in College and Universities[J]. JOURNAL OF CHANGSHA UNIVERSITY OF SCIENCE \& TECHNOLOGY(SOCIAL SCIENCE),2018,33(01):130136.(In Chinese)

[4] Yin Wandong. Deep Integration of Ideological and Political Education and Professional Course Teaching in Colleges. Journal of Fuzhou University (Philosophy and Social Sciences) ,2018,32(03):103-106.

[5] Zhang Aiqing. New Progress in Attribution Theory Research [J]. Educational Research and Experiment, 2003(01):38-41. ( In Chinese)

[6] Wang Peng. The Important Value and Significance of "Never Forget Why You Started" in General Secretary Xi Jinping's "July 1 Speech". Journal of Guangdong Institute of Socialism, 2017(04):5-7. 